\title{
The Economic Burden of Pediatric Asthma in the United States: Literature Review of Current Evidence
}

\author{
Richard Perry ${ }^{1}$. George Braileanu ${ }^{1} \cdot$ Thomas Palmer $^{1} \cdot$ Paul Stevens $^{2}$
}

Published online: 13 October 2018

(c) The Author(s) 2018

\begin{abstract}
Asthma is a chronic respiratory disease that is widespread throughout the US population and disproportionately affects children. This literature review aimed to identify recent information regarding the economic burden of pediatric asthma in the US. MEDLINE, EMBASE, Econlit, and PsycINFO databases and gray literature sources were searched from January 2012 to January 2018 to capture relevant publications. Publications reporting on healthcare resource utilization and/ or healthcare costs of pediatric asthma were included $(n=8)$. Total direct costs of pediatric asthma were US $\$ 5.92$ billion in 2013. Average annual costs per child ranged from US\$3076 to US\$13612. Across studies, pharmacy (US\$1027-2120), inpatient (US\$337-2016) and outpatient (US\$1049-8039) costs were the primary contributors to healthcare costs. Inpatient and emergency department (ED) visits exerted a high economic burden. For instance, the national annual cost of asthmarelated hospitalizations was estimated at US\$1.59 billion in 2009, while estimates of costs-per-hospitalization (2010) and charges-per-discharge (2009) were US $\$ 3600$ and US\$8406, respectively. The total cost of ED visits to Medicaid was estimated at US\$272 million in 2010. In a mixed-insurance population, ED cost estimates ranged from US\$152 to US\$172 annually per patient. Invariably, costs for children with asthma were significantly greater than for children without. Pediatric asthma imposes a significant economic burden to the US healthcare system. Children with asthma have significantly higher healthcare resource utilization and costs than children without asthma.
\end{abstract}

\section{Key Points for Decision Makers}

Pediatric asthma imposes a substantial economic burden on the US healthcare system through increased healthcare utilization and costs.

Children with asthma have significantly higher healthcare utilization rates than children without asthma.

\section{Introduction and Objectives}

Asthma is a chronic inflammatory respiratory disease characterized by recurrent airway obstruction leading to a number of symptoms, often in response to environmental

Paul Stevens

paul.stevens@eu.omron.com

Adelphi Values, Manchester, UK

2 OMRON Healthcare Europe B.V., Hoofddorp, The Netherlands triggers [1]. Symptoms include episodes of breathlessness, coughing, wheezing, chest pain, and chest tightness, which, when severe, can be life threatening [1]. For most patients, depending on severity, asthma may be effectively managed through avoidance of triggers, regular use of controller medication (often inhaled corticosteroids), and as-needed use of reliever medication to prevent exacerbations [1].

According to the most recent National Health Interview Survey (NHIS), the US Centers for Disease Control and Prevention (CDC) estimates that around 26 million individuals in the USA had asthma in 2016, of which 6 million were children younger than 18 years old [2]. School-aged children and poorer families were disproportionately affected; compared with the national asthma prevalence of $8.3 \%$, the prevalence in children aged 5-14 years was $10.1 \%$ and amongst those below the federal poverty threshold asthma prevalence was 11.8\% [2]. Between 2001 and 2010, asthma prevalence amongst individuals of all ages rose by $2.9 \%$ each year [3].

Asthma has previously been shown to be associated with a significant economic burden [4-6]. More than 50\% of pediatric current asthma sufferers reported experiencing one or more asthma attacks in 2016 [2], which can lead to substantial healthcare resource use and cost if not controlled or 
managed appropriately. Furthermore, according to results of a recent CDC surveillance study, children with asthma aged 0-17 years had higher rates of physician office visits, hospital outpatient visits, and emergency department (ED) visits than adults aged 18 years and over in the USA [3]. Indeed, asthma is the third most common cause of hospitalization in children younger than 15 years old [7].

Using 1996 data, Wang et al. [6] estimated the total annual direct and indirect costs of pediatric asthma in the USA at US\$2 billion. More recent estimates indicate the total direct and indirect cost was US\$18 billion in 2005 for an adult population in the USA [5]; the combined direct and indirect cost of pediatric and adult asthma populations was US\$56 billion in 2007 [4]. However, neither of these studies provide a pediatric-specific breakdown of costs, indicating there is a lack of recent data related to the economic burden of pediatric asthma in the USA.

The primary objective of this literature review was to identify recent studies that report on the healthcare and cost burden of pediatric asthma in the USA.

\section{Methodology}

\subsection{Literature Search}

\subsubsection{Electronic Database Search}

A search of the literature for studies reporting on the economic burden of pediatric asthma, published between 1 January 2012 and 23 January 2018, was conducted in four biomedical and economic databases via the OVID platform: EMBASE, MEDLINE, PsycINFO, and EconLit. Given the exclusive focus on US-specific data, the electronic database search was limited to articles published in English. The search was limited to 2012 initially to capture the most recent 5-year data (due to fluctuations of healthcare costs over time), whilst ensuring that the review captured sufficient data. The search was eventually run in 2018, with the original limit of 2012 retained.

An overview of the search strategy is provided in Table 1. An additional filter was also developed to identify any publications specifically reporting on the economic burden of pediatric wheeze. The 38 records identified using this additional filter were screened concurrently with the rest of the identified records.

\subsubsection{Gray Literature Review}

A further search of internet-based sources relating to the economic burden of pediatric asthma (limited to English language only and post-2012 publication) was also undertaken using no predefined search criteria. This gray literature review comprised of searching the reference lists of key publications and other literature reviews, in addition to key conference proceedings (i.e., European Respiratory Society Annual Congress 2017; Pediatric Asthma and Allergy Meeting 2017; American Academy of Allergy, Asthma and Immunology Congress 2017); websites of national bodies and patient groups (Allergy and Asthma network; Asthma and Allergy Foundation of America); and registries and results databases of clinical studies (ClinicalTrials.gov).

\subsubsection{Study Selection}

Predetermined inclusion and exclusion criteria were used to assess the eligibility of identified abstracts and full texts for inclusion. All screening (by title and abstract, and by full

Table 1 OVID search strategy

\begin{tabular}{|c|c|c|}
\hline No. & Search & $\begin{array}{l}\text { Hits (23 } \\
\text { January } \\
\text { 2018) }\end{array}$ \\
\hline 1 & Asthma/ or Asthma.mp. & 427,439 \\
\hline 2 & Exp Pediatrics/ or exp child/ or ( $\mathrm{p}$ ?ediatric* or child* or infant*).ab,ti. & $6,258,766$ \\
\hline 3 & $\begin{array}{l}\text { Exp health care costs/ or cost of illness/ or economics, hospital/ or economics, medical/ or (cost or <economic burden>). } \\
\text { ab,ti. }\end{array}$ & $1,199,957$ \\
\hline 4 & $\begin{array}{l}\text { Emergency service, hospital/ or emergency ward/ or hospital/ or hospitalization/ or }(<\text { emergency room }>\text { or }<\text { emergency } \\
\text { department }>\text { or }<\text { emergency ward }>\text { or }<\text { resource use }>\text { or }<\text { resource utili?ation }>\text { ).ab,ti. }\end{array}$ & $1,089,506$ \\
\hline Subtotal & 1 and 2 and 3 and 4 & 1276 \\
\hline Total $^{a}$ & Economic impact of pediatric asthma & 408 \\
\hline 5 & $\begin{array}{l}\text { Respiratory sounds/ or < abnormal respiratory sound }>\text { / or respiratory sounds/ or auscultat*/ or (wheez* or } \\
\text { difficult*adj1breath* or whistl*).mp. }\end{array}$ & 56,536 \\
\hline Subtotal & 1 and 2 and 3 and 4 and 5 & 90 \\
\hline Total $^{a}$ & Economic impact of undetected wheeze & 38 \\
\hline
\end{tabular}

${ }^{a}$ Limits (English language and 2012-current publication year) applied and deduplicated 
text) was performed by one reviewer and included publications were discussed with a second reviewer to resolve any uncertainties. Publications were included if they reported on the healthcare resource utilization (HRU) or healthcare costs associated with asthma/wheeze for pediatric patient populations in the USA. Publications were excluded if they did not report on pediatric patients with a confirmed asthma diagnosis, did not report any information concerning the healthcare costs or HRU of pediatric asthma, or reported economic burden information relating to misdiagnosis of asthma. Studies conducted in patient populations outside of the USA as well as cost-effectiveness studies, editorials, letters, commentaries, and non-human studies were also excluded.

\subsubsection{Data Extraction and Analysis}

Relevant HRU and associated cost data (e.g., ED visits, hospitalizations/inpatient stays, outpatient visits, and pharmacy or treatment usage) were extracted into a data extraction form and qualitatively evaluated for inclusion into the literature review by one reviewer.

\section{Results}

\subsection{Literature Search Results}

A total of 1310 records were identified from the database searches. After application of the limits and deduplication, the titles and abstracts of 408 records were screened using the inclusion/exclusion criteria described in Sect. 2.1.3. A total of 372 records were excluded, and 36 records were included for full-text review. Of these 36 full texts, seven were eligible for data extraction and inclusion into the literature review. One further publication was identified for inclusion through gray literature searching; therefore, a total of eight publications were included in this review [8-15]. The results of the literature searches and study selection process are presented in Fig. 1.

The characteristics and outcomes reported in the studies identified by the literature review are presented in Tables 2 and 3, respectively. Two studies were longitudinal analyses $[8,10]$ and four studies were cross-sectional analyses $[11$, $12,14,15]$. Two studies were cost analyses-one modelling savings associated with increasing asthma medication adherence and the other collating data from various sources on asthma costs $[9,13]$.

Six studies reported nationwide data $[8,10-12,14,15]$, one reported data from 14 Southern states [13], and one reported data from a specific region (Table 2) [9]. Identified studies covered patients enrolled in all major insurance plans: three studies used a mixed insurance sample $[8,10,14]$, one used data from private insurers only [11], and three used a solely Medicaid-enrolled population (Table 2) [12, 13, 15]. Data collection spanned more than 15 years, from 1997 to 2013, and covered all ages from birth to 18 years old (Table 2) [8-15].

Each outcome relating to HRU and costs was reported by two or more studies (Table 3). For instance, inpatient resource use and costs were the most widely reported, with six publications providing data [8-11, 14, 15], whereas outpatient resource use and costs were the least well reported, with data available from three publications (Table 3) $[9,14,15]$.

Children with asthma were defined based on the International Classification of Diseases, Ninth Revision (ICD9) diagnosis code 493 (asthma) code in six studies [8-10, $12,13,15]$, ICD-9 code 493 or more than two claims for asthma medication in one study [11], and ICD-9 code 493 or positive responses to questioning in one study (Table 2) [14].

Two studies provided comparisons between children with and without asthma [14, 15]. Sullivan et al. [14] was a retrospective cross-sectional analysis of data from all children in the Medical Expenditure Panel Survey. This was a household survey, where children with asthma were defined as those whose caregivers gave a positive response to both the questions "Have you ever been diagnosed with asthma?" and "Do you still have asthma?" [14]. If the responses to these questions were negative, children were still considered as having asthma if they had medical claims filed under the ICD-9 code 493. Children without asthma were defined as subjects in the sample that did not positively respond to the questions and did not have claims with the ICD-9 code 493 [14]. Zhang et al. [15] was a case-control study that included patients with Medicaid claims with balanced demographic characteristics and comorbidities between the case (children with asthma) and control (children without asthma) cohorts to ensure accurate comparisons. To differentiate patients, Zhang et al. [15] similarly used the ICD-9 code 493 to define children with asthma. Although not explicitly stated, the authors of this current article assumed that children without asthma referred to individuals that did not have any HRU with the ICD-9 code 493.

\subsection{Healthcare Resource Utilization}

This literature review identified six studies that reported on HRU [8, 10-12, 14, 15]. More specifically, ED visits were reported in three studies [11,12,14], inpatient stays in five studies $[8,10,11,14,15]$, outpatient visits in two studies $[14,15]$, and treatments in two studies [14, 15]. A summary of HRU findings is provided in Table 4. 


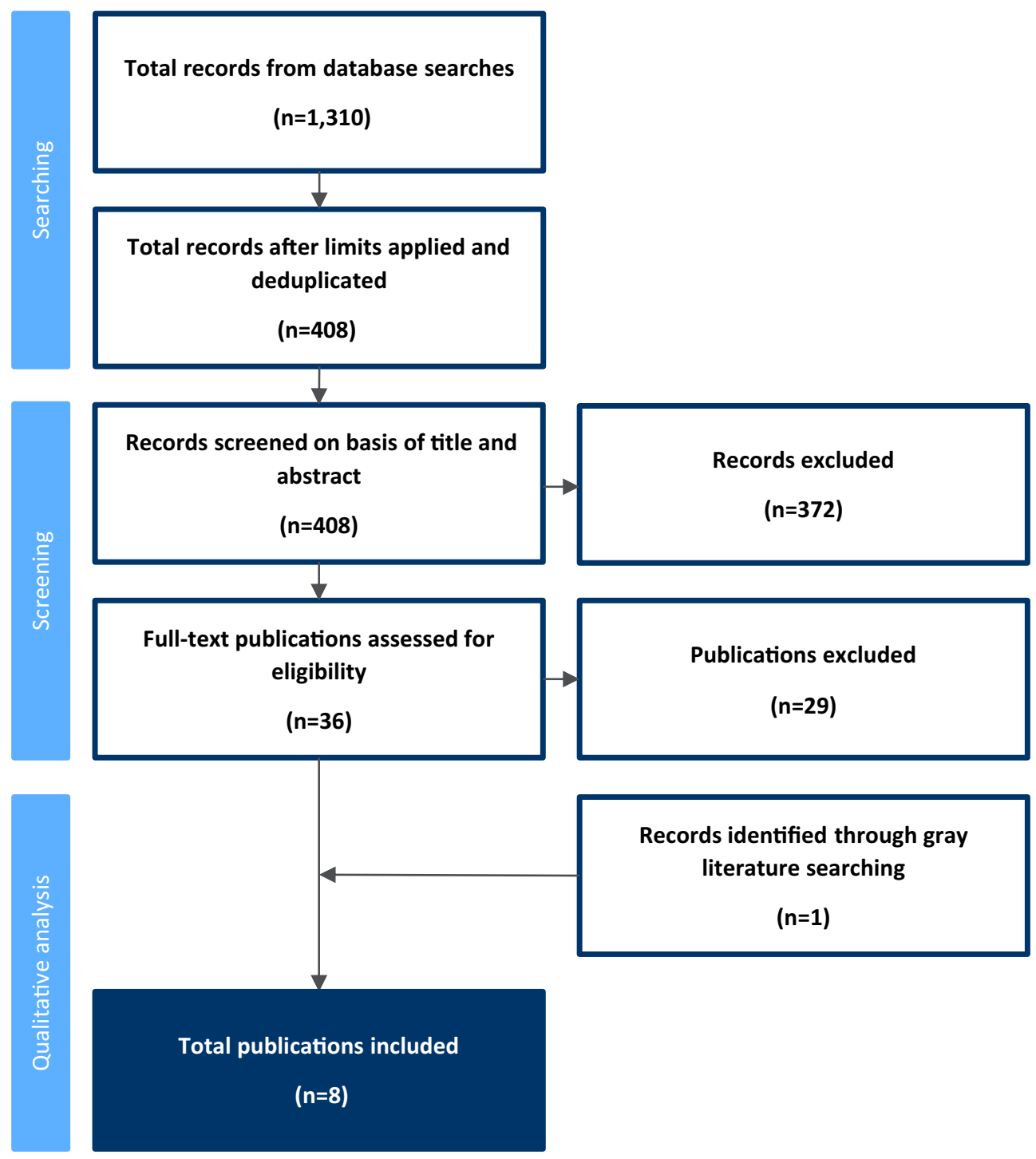

Fig. 1 Literature review flow diagram

\subsubsection{Emergency Department Visits}

Data for ED visits were reported in three observational studies for pediatric patients aged $0-17$ years $[11,12,14]$. There was some degree of heterogeneity, with one study reporting the mean number of ED visits [14], while the remaining studies reported the total number of ED visits for the entire sample [11, 12].

Children with asthma experienced significantly more allcause ED visits per year than children without asthma (0.21 vs. $0.11 ; p<0.001$ ), according to the results of a large retrospective study of 5890 school-aged children with asthma [14].

Two studies reported highly variable total asthma-related ED visits, as a proportion of the sample, likely due to the differences in population sizes and characteristics. The total number of asthma-related ED visits reported by Pearson et al. [12] was 628,759 , accounting for approximately $19 \%$ of the total sample $(N=3,313,869,0-17$ years, unadjusted rate). In contrast, Karaca-Mandic et al. [11] reported the proportion of asthma-related ED visits among children aged between 5 and 18 years old ranging from 3.3 to $3.7 \%$ (195-220 total visits; study sample $N=5913$ ) and aged $<5$ years old ranging from 7.1 to $7.9 \%$ (207-231 total visits; study sample $N=2921$, unadjusted analyses) [11].

\subsubsection{Inpatient Visits}

The HRU relating to inpatients encompasses hospitalizations and the associated length of stay (LOS). Data on the number or rate of hospitalizations were presented in five 


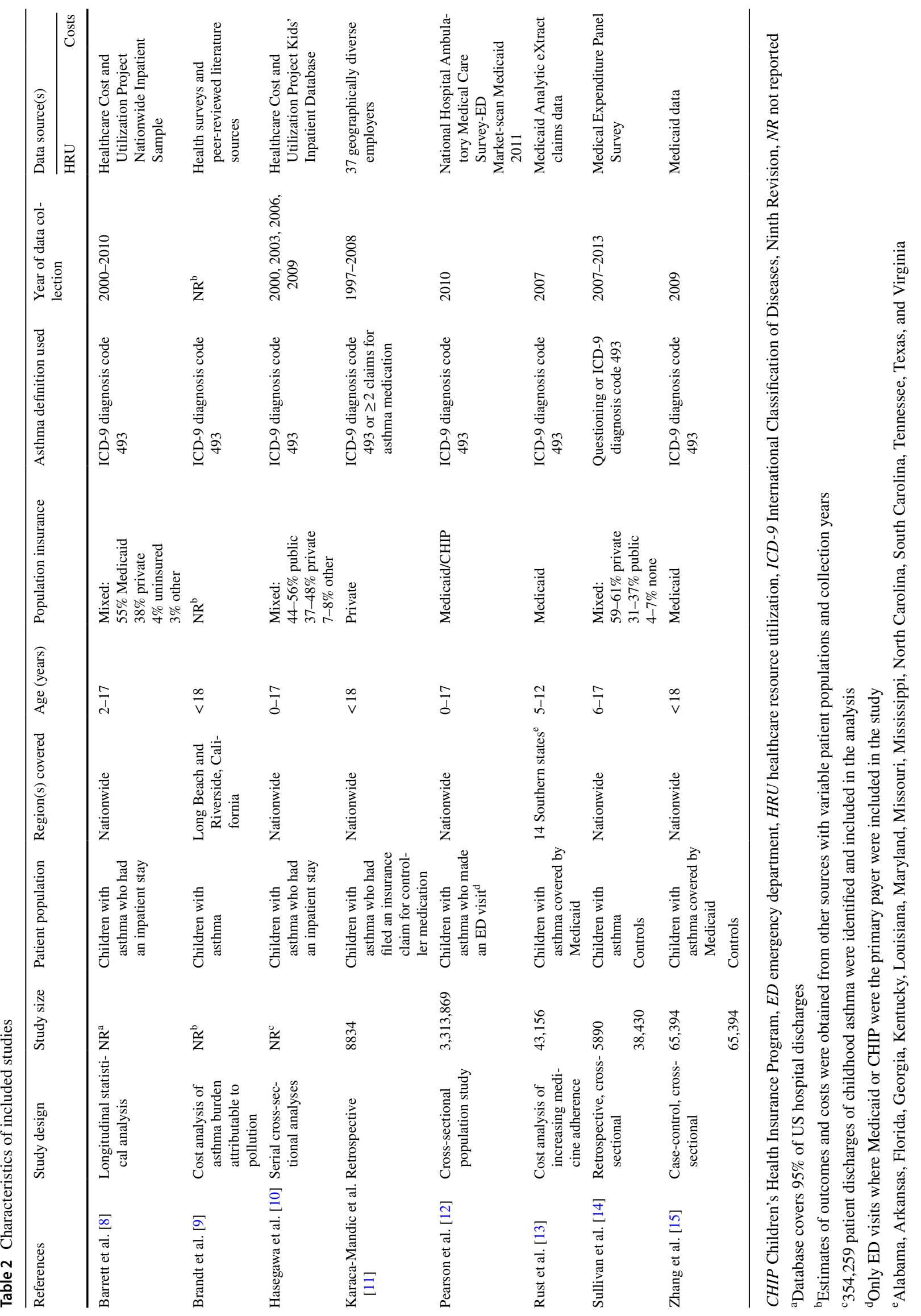




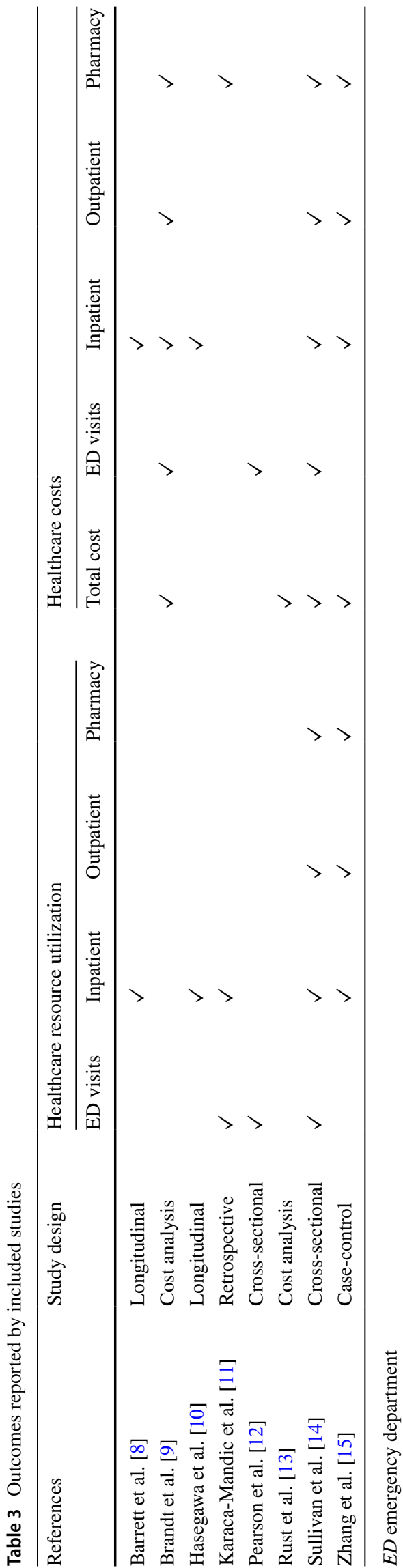

observational studies $[8,10,11,14,15]$. One study also reported LOS [10].

According to one of the studies, asthma was responsible for $2.3 \%$ of all hospitalizations in patients younger than 18 years from 2000 to 2009 [10]. In other studies, the proportion of hospitalizations among children with asthma varied widely, ranging from $2.10 \%$ (data collected from 1997 to 2008) to as high as $11.65 \%$ (2009 data) [11, 15]. Higher hospitalization rates (4.7-5.6\%) were also reported in children younger than 5 years than in children aged $5-18$ years $(2.1-2.2 \%)$ [11].

Two studies reporting hospitalization data from Healthcare Cost and Utilization Project (HCUP) databases-one reporting data every year from 2000 to 2010 and the other reporting data every 3 years from 2000 to 2009-showed declines in hospitalizations over time $[8,10]$. The rate of hospitalizations decreased from 165 to 130 per 100,000 people and from 21.1 to 18.4 per 10,000 person-years (both $p<0.001$; Fig. 2) [8, 10]. Likewise, the LOS per hospitalization and the total number of inpatient days associated with pediatric asthma decreased from 2.0 to 1.9 $(p<0.001)$ and from 364,000 to 305,000 , respectively, from 2000 to 2009 [10].

Children with asthma were significantly more likely to require hospitalization than children without, irrespective of insurance provider. For example, using a mixed insurance sample, the mean number of hospitalizations per year for children with asthma was 0.03 compared with 0.02 for children without asthma $(p<0.001)$ [14]. In a Medicaid-only dataset the differences were even more pronounced, as children with asthma were four times more likely to experience hospitalizations $(11.65 \%$ vs. $2.84 \%$; $p<0.0001)$ and twice as likely to require long-term care $(2.75 \%$ vs. $1.27 \% ; p<0.0001)$ than children without asthma [15].

\subsubsection{Outpatient Visits}

Two cross-sectional studies reported on the rate or number of outpatient visits $[14,15]$. Definitions of what constituted outpatient visits were not provided in either of these two studies.

Children with asthma experienced significantly more outpatient visits than children without, whether reporting as an average annual number of visits per child [14] or as a proportion of children requiring an outpatient visit [15]. Sullivan et al. [14] reported that children with asthma average 5.13 annual outpatient visits, compared with 2.90 for children without asthma $(p<0.001)$. Similar results were reported in the study by Zhang et al. [15], where $99.99 \%$ of children with asthma had an outpatient visit, compared with $84.72 \%$ of children without $(p<0.0001)$ [15]. 
Table 4 Key healthcare resource utilization findings for children with asthma reported by included studies

\begin{tabular}{|c|c|c|c|c|c|c|c|c|}
\hline \multirow[t]{2}{*}{ References } & \multirow{2}{*}{$\begin{array}{l}\text { Year(s) of } \\
\text { data collec- } \\
\text { tion }\end{array}$} & \multirow{2}{*}{$\begin{array}{l}\text { Outcome meas- } \\
\text { urement }\end{array}$} & \multirow[t]{2}{*}{ ED visits } & \multicolumn{3}{|l|}{ Inpatient } & \multirow[t]{2}{*}{ Outpatient visits } & \multirow[t]{2}{*}{ Treatments } \\
\hline & & & & Hospitalizations & Length of stay & Long-term care & & \\
\hline \multicolumn{9}{|c|}{ Observational studies } \\
\hline Barrett et al. $[8]^{\mathrm{a}}$ & 2010 & $\begin{array}{l}\text { Rate of hospi- } \\
\text { tal stays per } \\
100,000 \text { popula- } \\
\text { tion }\end{array}$ & & 130 & & & & \\
\hline \multirow[t]{2}{*}{$\begin{array}{l}\text { Hasegawa et al. } \\
{[10]^{\mathrm{a}}}\end{array}$} & 2009 & $\begin{array}{l}\text { Rate of hospi- } \\
\text { talizations per } \\
10,000 \text { person- } \\
\text { years }\end{array}$ & & 18.4 & & & & \\
\hline & & $\begin{array}{l}\text { Length of stay } \\
\text { (days) }\end{array}$ & & & 1.9 & & & \\
\hline $\begin{array}{l}\text { Karaca-Mandic } \\
\text { et al. [11] }\end{array}$ & 1997-2008 & $\begin{array}{l}\text { Proportions of } \\
\text { patients }^{\mathrm{b}}\end{array}$ & $3.3-7.9$ & $2.1-5.6$ & & & & \\
\hline $\begin{array}{l}\text { Pearson et al. } \\
\text { [12] }\end{array}$ & 2010 & Total visits & 628,759 & & & & & \\
\hline $\begin{array}{l}\text { Sullivan et al. } \\
\text { [14] }\end{array}$ & 2007-2013 & $\begin{array}{l}\text { Mean number per } \\
\text { patient }\end{array}$ & 0.21 & 0.03 & & & 5.13 & $6.97^{\mathrm{c}}$ \\
\hline Zhang et al. [15] & 2009 & $\begin{array}{l}\text { Proportions of } \\
\text { patients }^{\mathrm{b}}\end{array}$ & & 11.65 & & 2.75 & 99.99 & $96.53^{\mathrm{d}}$ \\
\hline
\end{tabular}

$E D$ emergency department

${ }^{\mathrm{a}}$ Most recent estimate reported

${ }^{\mathrm{b}}$ Proportions of patients in the full sample

${ }^{\mathrm{c}}$ Mean number of prescriptions per patient

${ }^{\mathrm{d}}$ Defined as pharmacy utilization

Fig. 2 Hospitalizations associated with pediatric asthma per 100,000 population (a) and per 10,000 person-years $(\mathbf{b})[8,10]$
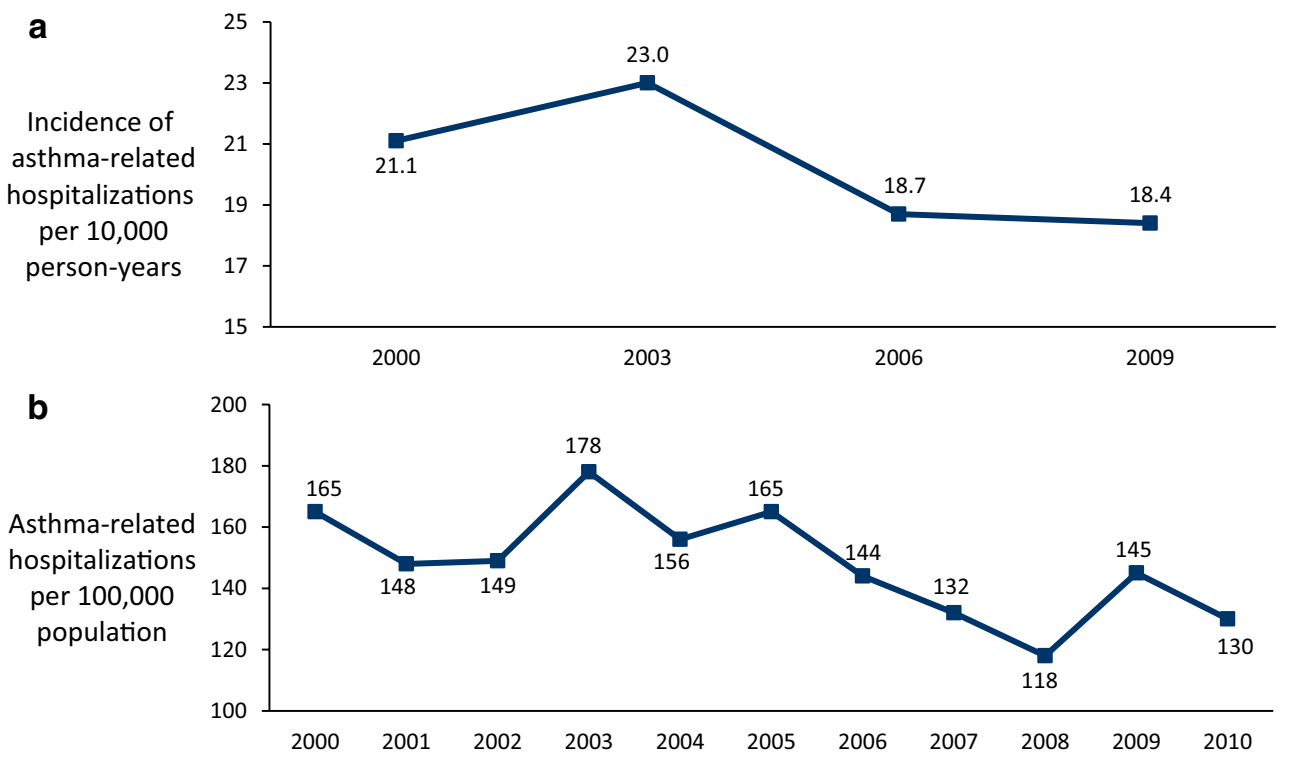

\subsubsection{Pharmacy Utilization}

Two cross-sectional studies reported the number of prescriptions or likelihood of pharmacy use for children with asthma $[14,15]$.
Data were reported as the mean number of prescriptions [14], or the proportion of patients who used the pharmacy [15]. On average, children with asthma received 6.97 annual prescriptions compared with a mean of 1.98 annual prescriptions given to children without asthma $(p<0.001)$ [14]. 
Similar results were seen in another study, where the proportion of children with asthma from a Medicaid cohort who used the pharmacy was also significantly greater than children without asthma (96.53\% vs. $64.40 \% ; p<0.0001)$ [15].

\subsection{Healthcare Costs}

The second component of the economic burden of disease is the cost associated with HRU. All eight studies identified reported on healthcare costs [8-15]. Specifically, data on the total costs of pediatric asthma were reported in four studies [9, 13-15]; data on ED costs in three studies [9, 12, 14]; data on inpatient costs in five studies [8-10, 14, 15]; data on outpatient costs in three studies [9, 14, 15]; and data on treatment costs in four studies $[9,11,14,15]$. A summary of healthcare cost findings is provided in Table 5.

\subsubsection{Total Cost of Pediatric Asthma}

This literature review identified one study estimating the total cost of pediatric asthma to the USA [14], three studies that reported the total cost per case $[9,14,15]$, and one cost analysis study reporting cost saving associated with increasing medication adherence [13].

Sullivan et al. [14] estimated that the total direct cost of pediatric asthma to the USA in 2013 was US\$5.92 billion (2015 dollars). This figure was derived from analysis of data from a nationally representative database of 44,670 children aged 6-17 years, of which 5890 (13.3\%) reported having current asthma. This population included patients covered by all types of insurers [14].

Average annual costs per child with asthma ranged from US\$3076 (2015 dollars) to US\$13,612 (dollar valuation year not reported) $[9,14,15]$. When compared to children without asthma, children with asthma had significantly higher total annual costs (US\$3076-13,612 vs. US\$1628-6695) $[14,15]$.

Increasing medication adherence could also provide a saving-Rust et al. [13] used a model to determine the level of savings achieved by improving inhaled corticosteroid medication adherence rates. According to the study findings, high adherence rates could reduce total cost from US\$4969.31 to US\$4017.25 per patient (dollar valuation year not reported) [13].

\subsubsection{Emergency Department Costs}

One cross-sectional study reported a state-by-state breakdown of ED costs [12], and another cross-sectional study and one cost analysis reported ED costs per typical patient $[9,14]$.

Pearson et al. [12] estimated that, in 2010, there were 628,759 asthma-related ED visits where Medicaid/CHIP
(Children's Health Insurance Program) was the primary payer, resulting in a total national cost of US\$272 million (2011 dollars; per visit cost of US $\$ 433 ; N=3,313,869$ children with asthma covered by Medicaid/CHIP) [12].

Two cross-sectional studies which used mixed populations with all types of insurance estimated ED costs ranging from US\$152 (2015 dollars) to US\$172 (2010 dollars) on average per child per year [9, 14]. This was, however, still significantly greater than the estimated US\$84 (2015 dollars) average annual ED costs per child without asthma as calculated by Sullivan et al. [14] $(p<0.001)$.

\subsubsection{Inpatient Costs}

Two longitudinal studies were identified that reported the trend in total and per patient inpatient costs over time [8, 10]; three cross-sectional studies and one cost analysis were identified that reported the average annual inpatient cost per patient $[9,14,15]$.

As indicated in previous sections, there is conflicting evidence as to whether the cost of asthma-related hospitalizations is increasing [8, 10]. As was shown in Sect. 3.2.2), both Hasegawa et al. [10] and Barrett et al. [8] found falling rates of hospitalizations; however, Hasegawa et al. [10] found that the decline in incidence was offset by a rise in per-visit charges, such that the total national hospitalization charges associated with pediatric asthma rose by $26 \%$ from US\$1.27 billion in 2000 to US\$1.59 billion in 2009 (both 2009 dollars; $p<0.001$ ) [10]. Hasegawa et al. [10] calculated that, in 2009, these charges translated to direct costs of US\$502 million. Hospital charges reflect the list price for services, and are often much higher, due to later discounting, than the billed cost. The average hospital charge per hospitalization also rose by $29 \%$, from US\$5938 in 2000 to US\$8406 in 2009 (both 2009 dollars; $p<0.001$; Fig. 3). In contrast, Barrett et al. [8] reported that the average cost per hospitalization for a child with asthma from 2000 to 2010 remained relatively constant at around US\$3500 (2010 estimate $=$ US\$3600).

When compared with controls, inpatient costs associated with children with asthma were significantly higher than those without the condition. All-cause costs ranged from US\$337 (2015 dollars) to US\$2016 (dollar valuation year not reported) [9, 14, 15], significantly greater than estimates of US\$204 (2015 dollars) to US\$469 (dollar valuation year not reported) observed for children without asthma ( $p<0.001$ and $p<0.0001$, respectively) $[14,15]$.

\subsubsection{Outpatient Costs}

Three studies identified reported outpatient costs [9, 14, 15]. Estimated all-cause outpatient costs per patient ranged from US\$1049 (2015 dollars) to US\$8039 (dollar valuation year 
Table 5 Key healthcare cost findings for children with asthma reported by included studies

\begin{tabular}{|c|c|c|c|c|c|c|c|c|c|}
\hline \multirow[t]{2}{*}{ References } & \multirow{2}{*}{$\begin{array}{l}\text { Year(s) of } \\
\text { data collec- } \\
\text { tion }\end{array}$} & \multirow{2}{*}{$\begin{array}{l}\text { Year of } \\
\text { dollar valu- } \\
\text { ation }\end{array}$} & \multirow{2}{*}{$\begin{array}{l}\text { Outcome } \\
\text { measurement }\end{array}$} & \multirow{2}{*}{$\begin{array}{l}\text { Total cost } \\
\text { (US\$) }\end{array}$} & \multirow{2}{*}{$\begin{array}{l}\text { ED visits } \\
\text { (US\$) }\end{array}$} & \multicolumn{2}{|c|}{ Inpatient (US\$) } & \multirow{2}{*}{$\begin{array}{l}\text { Outpatient } \\
\text { visits (US\$) }\end{array}$} & \multirow{2}{*}{$\begin{array}{l}\text { Treatments } \\
\text { (US\$) }\end{array}$} \\
\hline & & & & & & $\begin{array}{l}\text { Hospitaliza- } \\
\text { tions }\end{array}$ & $\begin{array}{l}\text { Long-term } \\
\text { care }\end{array}$ & & \\
\hline \multicolumn{10}{|c|}{ Observational studies } \\
\hline $\begin{array}{l}\text { Barrett et al. } \\
{[8]^{\mathrm{a}}}\end{array}$ & 2010 & 2010 & Cost per stay & & & 3600 & & & \\
\hline \multirow[t]{2}{*}{$\begin{array}{l}\text { Hasegawa } \\
\text { et al. }[10]^{\mathrm{a}}\end{array}$} & 2009 & 2009 & $\begin{array}{l}\text { Total annual } \\
\text { national } \\
\text { charges } \\
\text { associ- } \\
\text { ated with } \\
\text { pediatric } \\
\text { asthma }^{\text {b }}\end{array}$ & & & 1.59 billion & & & \\
\hline & & & $\begin{array}{l}\text { Hospital } \\
\text { charges per } \\
\text { discharge }^{\mathrm{b}}\end{array}$ & & & 8406 & & & \\
\hline $\begin{array}{l}\text { Karaca-Man- } \\
\text { dic et al. } \\
{[11]}\end{array}$ & 1997-2008 & 2010 & $\begin{array}{l}\text { Annual out- } \\
\text { of-pocket } \\
\text { costs per } \\
\text { child }\end{array}$ & & & & & & $151-154^{\mathrm{c}}$ \\
\hline \multirow[t]{2}{*}{$\begin{array}{l}\text { Pearson et al. } \\
\text { [12] }\end{array}$} & 2010 & 2011 & $\begin{array}{l}\text { Annual total } \\
\text { cost for } \\
\text { the study } \\
\text { population }\end{array}$ & & $272,454,000$ & & & & \\
\hline & & & Cost per visit & & 433 & & & & \\
\hline \multirow[t]{2}{*}{$\begin{array}{l}\text { Sullivan } 2017 \\
\text { [14] }\end{array}$} & 2007-2013 & 2015 & $\begin{array}{l}\text { Total annual } \\
\text { national } \\
\text { cost of } \\
\text { pediatric } \\
\text { asthma }\end{array}$ & 5.92 billion & & & & & \\
\hline & & & $\begin{array}{c}\text { Annual cost } \\
\text { per child }\end{array}$ & 3076 & 152 & 337 & & 1049 & $1027^{\mathrm{d}}$ \\
\hline $\begin{array}{l}\text { Zhang et al. } \\
\text { [15] }\end{array}$ & 2009 & NR & $\begin{array}{c}\text { Annual cost } \\
\text { per child }\end{array}$ & 13,612 & & 2016 & 1437 & 8039 & $2120^{\mathrm{e}}$ \\
\hline \multicolumn{10}{|l|}{ Cost analyses } \\
\hline $\begin{array}{l}\text { Brandt et al. } \\
\text { [9] }\end{array}$ & Mixed $^{\mathrm{f}}$ & 2010 & $\begin{array}{c}\text { Annual cost } \\
\text { per child }\end{array}$ & $3819-4008$ & $170-172$ & $529-531$ & & $231-239^{\mathrm{g}}$ & $749^{\mathrm{h}}$ \\
\hline Rust et al. [13 & 2007 & NR & $\begin{array}{c}\text { Annual cost } \\
\text { per child }\end{array}$ & $4969.31^{\mathrm{i}}$ & & & & & \\
\hline
\end{tabular}

$E D$ emergency department, $N R$ not reported

${ }^{a}$ Most recent estimate reported

${ }^{\mathrm{b}}$ Note that charges are the list price for services and may not represent the final billed amount

'Unspecified 'basket' of asthma medicine

${ }^{\mathrm{d}}$ Cost of prescriptions

${ }^{\text {e}}$ Pharmacy costs

${ }^{\mathrm{f}}$ Draws on data from multiple sources to produce cost estimate

${ }^{\mathrm{g}}$ Asthma-specific office visits

${ }^{\mathrm{h}}$ Includes inhaled corticosteroids, cromolyn, and albuterol

${ }^{\text {i }}$ Cost based on current percentage of patients with 'good' medicine adherence (control medicine claims to total medicine claims ratio $>0.5$

not reported) for children with asthma and were significantly greater than children without the condition (US\$592-4585; $p<0.001$ and $p<0.0001$ ) [14, 15]. Annual outpatient costs for children with asthma estimated by Brandt et al. [9] were far lower, from US\$231 to US\$239 (2010 dollars). However, these estimates were for asthma-specific office visits, unlike the all-cause outpatient visits estimated by the other studies [9]. 
Fig. 3 Total cost of asthmarelated hospitalizations and hospital charges per discharge [10]. $b n$ billion

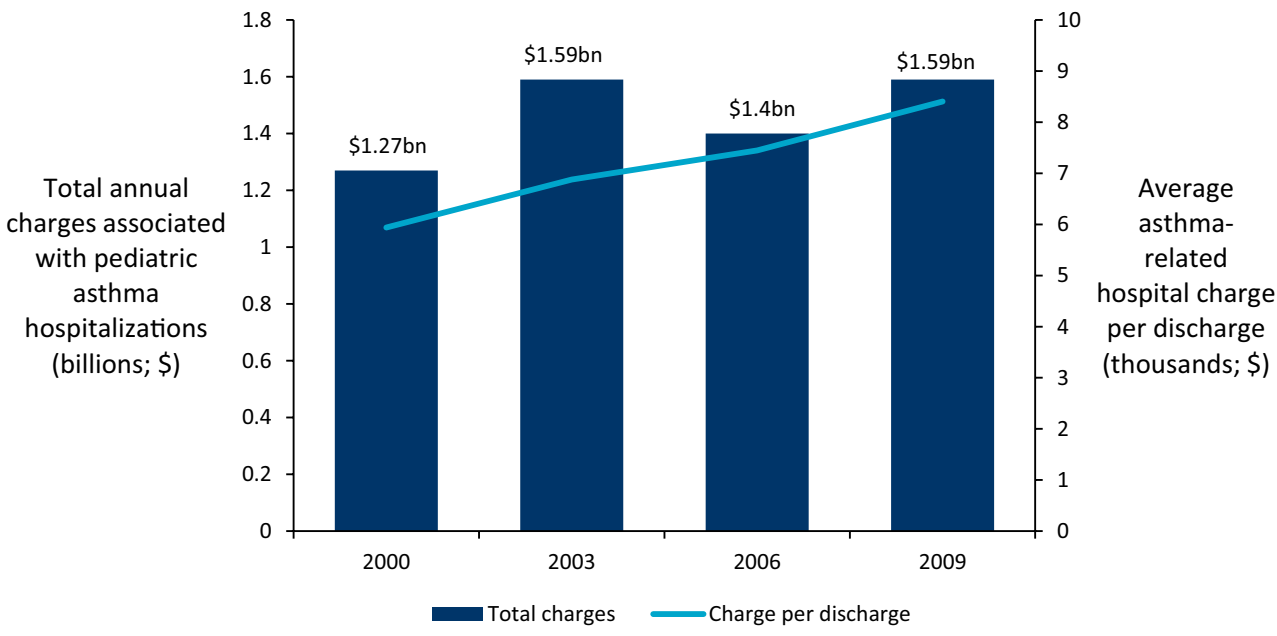

\subsubsection{Pharmacy Costs}

As shown in previous sections, children with asthma claim more prescriptions and use the pharmacy more than children without the condition [14, 15]. For many children with asthma, effective therapy requires regular administration of inhaled corticosteroids [1], which can lead to increased pharmacy costs $[14,15]$. Three cross-sectional studies [11, $14,15]$ and one cost analysis [9] reported pharmacy/prescription costs.

There were several differences in the reporting of cost data. Two studies reported the average annual cost of pharmacy use per child with asthma from US\$1027 (2015 dollars; mixed insurance population) [14] to US\$2120 (dollar valuation year not reported; Medicaid-enrolled children) [15], significantly greater than the calculated US\$257-968 average annual cost for children without asthma $(p<0.001$ and $p<0.0001)[14,15]$. In a privately insured population, the average annual out-of-pocket cost for a child with asthma was between US\$151 and US\$154 (2010 dollars) for a typical 'basket' of medicine [11]. Brandt et al. [9] reported the total annual cost for three common medicines and found that more is spent on albuterol (reliever; US\$374 annual average per child with asthma) than on inhaled corticosteroids (controller; US\$273) and on cromolyn (anti-inflammatory; US\$102) (all 2010 dollars) [9].

\section{Discussion}

The results of this literature review suggest that the economic burden of pediatric asthma in the USA is large. Total direct costs of pediatric asthma were estimated at US\$5.92 billion in 2013 [US\$6.31 billion in 2018 dollars, adjusted for inflation for reference only using the Bureau of Labor Statistics Consumer Price Index calculator (https ://www.bls.gov/data/inflation_calculator.htm)] [14]. Acute care visits are significant contributors to this burden-one study estimated total national charges of asthma-related hospitalizations at US\$1.59 billion in 2009 (US\$1.86 billion in 2018 dollars) [10], while a different study estimated the cost of asthma-related ED visits to Medicaid only to be US\$272 million in 2010 (US\$313 million in 2018 dollars) [12]. Annually, for an average child with asthma, this translates to a total cost of US\$3076 (US\$3279 in 2018 dollars) [14]. Per discharge, the hospital charges for an asthmarelated hospitalization were US\$8406 in 2009 (US\$9815 in 2018 dollars) [10]. Per visit, an asthma-related ED visit cost Medicaid US\$433 in 2010 (US\$498 in 2018 dollars) [12]. Tables 2 and 3 provide a summary of the HRU and cost outcomes reported by included studies.

The study by Sullivan et al. [14] reported the most outcomes pertinent to the objectives of this review and is, as stated by the authors, the only national study on the cost of pediatric asthma since Wang et al. [6] in 2005. The economic burden in these studies was calculated via different methods. For instance, when calculating the cost per average child with asthma, Sullivan et al. [14] controlled for more factors. In addition to controlling for age, sex, race, mother's education level, poverty status, and health insurance coverage [6], Sullivan et al. also controlled for region, number of chronic conditions, number of chronic conditions for each family member, health state of the reference person, and presence of a smoking family member [14]. However, the total direct cost ascribed to pediatric asthma-US $\$ 1.37$ billion (1996 data; 2018 dollars) versus US\$6.31 billion (2013 data; 2018 dollars)_has greatly increased, even when adjusted for inflation $[6,14]$. Though declared as representative, one limitation of the study by Sullivan et al. [14] is that the data source, the Medical Expenditure Panel Survey, did not capture data on asthma severity. Data from the CDC indicates that asthma severity (defined as either persistent or intermittent) is highly variable between US states [16]. The percentage of people with persistent asthma ranged from 
45.0\% in Oregon to $74.4 \%$ in Mississippi [16]. As the Medical Expenditure Panel Survey captures data on a comprehensive range of diseases, it is unlikely to account for geographical differences in the prevalence of persistent asthma. It is therefore possible that those with severe, or mild, asthma (and, respectively, greater, or lesser, HRU) may have been over- or under-sampled, and any effects from this have not been accounted for.

Average cost per child with asthma ranged from US $\$ 3076$ (US $\$ 3279$ in 2018 dollars) to US\$13,612 (not adjusted for inflation as valuation year was not reported) per year, in each case significantly greater than healthcare costs associated with children without asthma $[14,15]$. The disparity in costs may be due to the different datasets, with the higher estimate comprised entirely of Medicaid-enrolled children [15], while the lower estimate is comprised of a mixed insurance population [14]. It has previously been reported that children with asthma insured through Medicaid were more likely to experience more hospitalizations and ED visits than children with asthma insured through other providers $[17,18]$, providing an explanation for the higher associated costs. A second difference may be in the designs of the data sources used. As mentioned previously, Sullivan et al. [14] used data from the Medical Expenditure Panel Survey, a survey distributed to households across the USA to capture data on HRU and costs. Importantly, this sampling method captures healthy children with no HRU. In contrast, Zhang et al. [15] analyzed Medicaid data. Having a Medicaid claim (and being captured on this database) means that 'healthy' children with no claims are not captured, and therefore estimates may be comparatively higher. Having a claim also implies that the asthma is sufficiently severe to require HRU. As Sullivan et al. [14] also included patients with asthma on the basis of questioning, without necessarily having an ICD-9 code 493 claim, the sample may have had, on average, less severe asthma than the sample in Zhang et al. [15].

A further difference was in the data collection time: the data collected by Sullivan et al. [14] was spread across 7 years from 2007 to 2013, while the data collected by Zhang et al. [15] only provided a snapshot of the year 2009, which may be prone to time-period bias. For instance, asthma prevalence in children was increasing from 2001 up to 2010 (from 8.7 to $9.4 \%$ ), but was then followed by decreases to $8.3 \%$ by 2016 . This suggests that capturing a longer time period can provide more accurate estimations that take into account variations in patient population size [19].

Differences in the insurance status of populations investigated in the studies was a common theme throughout the review, and offers some explanation as to the dissimilarities in estimates throughout. Sullivan et al. [14], using an all-insurers sample, provided consistently lower HRU estimates than Zhang et al. [15], who used a Medicaid-enrolled population. Similarly, Pearson et al. [12], using a sample comprised solely of Medicaid-enrolled children, reported a greater proportion of patients with ED visits than KaracaMandic et al. [11], who used a sample covered by private insurance. These differences were also seen in cost estimates: Sullivan et al. [14], using a mixed-insurance population, reported consistently lower cost estimates than Zhang et al. [15], using a Medicaid-enrolled only population.

In studies that provided total cost breakdowns, the greatest contributor to overall costs were visits to outpatient facilities, which almost all children with asthma experienced, pharmacy utilization, and inpatient stays (Table 5) $[9,14$, 15]. Despite the reported high costs of outpatient visits and pharmacy use $[14,15]$, longitudinal data regarding the number or costs on asthma medication over time were not identified. It would be interesting to determine whether increasing controller medication adherence (thereby increasing the regular costs paid by parents), as proposed by Rust et al. [13], would reduce costs, rather than parents following poor medication adherence principles to save money and then requiring urgent care facilities as a result of exacerbations.

Costs due to urgent care-hospitalizations and ED visits-were also high. Hasegawa et al. [10] found that, whilst the number of hospitalizations declined, the total hospital charges for hospitalizations due to pediatric asthma rose by $26 \%$ between 2000 and 2009, to as much as US\$1.59 billion (US $\$ 1.86$ billion in 2018 dollars). In contrast, using a similar data source, Barrett et al. [8] found that, whilst the rate decreased, the cost per visit of hospitalizations remained relatively similar over a comparable time period. The higher estimate provided by Hasegawa et al. [10] may be explained by the fact that they reported hospital charges, rather than costs as reported by Barrett et al. [8]. Hospital charges reflect the list price for services, whereas costs reflect the actual expense that is paid for care. Furthermore, due to discounting, costs are likely to be much lower than charges, thus potentially leading to the lower value calculated by Hasegawa et al. [10]. It is still unclear why one estimate increased whilst the other decreased. This may be reflected in the different databases used: Hasegawa et al. [10] used a pediatric-focused database, whereas Barrett et al. [8] used a database covering both adults and children and extracted pediatric inpatient stays. Additionally, reporting of costs was different between the two studies: Hasegawa et al. [10] reported hospital charge data directly from the data source; Barrett et al. [8] instead used a charge-to-cost ratio to convert charge values to costs. This ratio was an estimate, and may have varied in its accuracy.

Like hospitalizations, ED visits also carried a significant burden. Pearson et al. [12] reported an annual total of 629,000 ED visits made by children with asthma covered by Medicaid/CHIP, costing US $\$ 272$ million (US\$313 million in 2018 dollars) nationwide [12]. In the cross-sectional, nationally representative study conducted by Sullivan et al. 
[14], the proportion of children covered by public insurance was approximately $37 \%$ of all children with asthma [14], suggesting that the total disease burden may be even higher when taking into consideration other types of insurance and uninsured individuals.

However, improving adherence to controller therapy could provide additional total savings of up to $20 \%$ per patient [13]. In a modelling study by Rust et al. [13], children with asthma were classified as either high adherence (more than half of asthma prescriptions were for controller medication) or low adherence (less than half of asthma prescriptions were for controller medication). The rationale behind this was that children who file more claims for controller medication reduce the amount of asthma exacerbations they experience, subsequently reducing their need for acute care [13]. A branching tree simulation was used to calculate cost outcomes associated with varying the proportion of patients in each adherence category, beginning with the observed level of adherence (33.35\%) [13]. Rust et al. [13] estimate a $20 \%$ reduction in costs when increasing the proportion of patients with high adherence to $100 \%$. Savings in this estimate are only comprised of the reductions in hospitalizations and ED visits [13], presumably because the direct consequence of poor medication adherence is likely to be more exacerbations, and greater urgent HRU. However, this does not capture outpatient visits, indicated previously as large contributor to the total cost of managing asthma $[14,15]$.

In addition to providing important information about the burden of pediatric asthma, studies identified in this review also have potential for use in future cost-effectiveness analyses. As studies with representative populations have been captured, analyses focusing on different subpopulations could also be possible. The results of the review have indicated that outpatient visits and pharmacy utilization are the greatest contributors to the burden of asthma. Of the outcomes reported by Sullivan et al. [14], standard errors were largest for inpatient and prescription costs. This variance may be explained by asthma severity outliers that were not recognized in the absence of stratification by severity - a principal feature of the disease that is not captured by the Medical Expenditure Panel Survey [14]. However, Hasegawa et al. [10] and Karaca-Mandic et al. [11] reported less variance in the mean hospital charges per discharge and for out-of-pocket medication costs, respectively. The lack of consistency in variance reported in these studies mean that inpatient and pharmacy, as well as outpatient inputs, could therefore be candidates for sensitivity analyses of future cost-effectiveness studies. Variance was poorly reported in other identified observational studies, with all other studies failing to give intervals or ranges for estimates [8, 12, 15]. It is important to also consider the age of the data: Sullivan et al. [14] collected data up to 2013, Hasegawa et al. [10] up to 2009 [10], and Karaca-Mandic et al. [11] to 2008, all predating this review by more than 5 years. Such research would therefore require validation by comparing outputs against previously published cost-effectiveness studies.

This literature review has several limitations. One of the identified studies used sources which use self-reported healthcare resource use and cost data, which is subject to recall bias [14]. Furthermore, many of the studies focused solely on Medicaid-enrolled populations [12, 13, 15], previously reported to use more healthcare than children on other insurance plans $[17,18]$, whereas only one study focused solely on private insurers [11]. To address these limitations, future studies could research the economic burden of pediatric asthma using a data source that is nationally representative, containing children insured through multiple providers, but that also captures data stratified by severity. To the authors' knowledge, such a database does not exist. It may therefore be necessary to conduct large-scale tailored questionnaires/interviews to obtain this data. Further, to ensure objectivity, future studies could take cost estimates from billing information, rather than subject recall. Such a study may provide more conclusive, and possibly more accurate, proof of the burden of pediatric asthma, indicate the additional burden attributable to increasing severity, and outline the key drivers of costs.

\section{Conclusions}

The findings of the literature review indicate a high economic burden associated with pediatric asthma. Given the current healthcare consumption observed in pediatric asthma populations, this condition continues to be a substantial public health issue with detrimental effects on both patients and healthcare systems.

\section{Compliance with Ethical Standards}

Funding This study was funded by OMRON Healthcare Co. Ltd. and was conducted by Adelphi Values Limited. All authors were involved in drafting the article and revising it critically for important intellectual content, and all authors approved the final version to be published.

Conflict of interest Paul Stevens is an employee of OMRON Healthcare Europe B.V. Richard Perry, George Braileanu, and Thomas Palmer are employees of Adelphi Values Limited (Adelphi Values Limited received budgetary compensation for involvement in the conduct of the literature review and the manuscript development).

Open Access This article is distributed under the terms of the Creative Commons Attribution-NonCommercial 4.0 International License (http://creativecommons.org/licenses/by-nc/4.0/), which permits any noncommercial use, distribution, and reproduction in any medium, provided you give appropriate credit to the original author(s) and the 
source, provide a link to the Creative Commons license, and indicate if changes were made.

\section{References}

1. Global Initiative for Asthma (GINA). Pocket guide for asthma management and prevention. GINA. 2018. https://ginasthma. org/2018-pocket-guide-for-asthma-management-and-prevention/. Accessed 30 Apr 2018.

2. Centers for Disease Control and Prevention. Most recent asthma data. 2018. https://www.cdc.gov/asthma/most_recent_data.htm. Accessed 2 Aug 2018.

3. Moorman JE, Akinbami LJ, Bailey CM, Zahran HS, King ME, Johnson CA, et al. National surveillance of asthma: United States, 2001-2010. Vital Health Stat 3. 2012;35:1-58.

4. Barnett SBL, Nurmagambetov TA. Costs of asthma in the United States: 2002-2007. J Allergy Clin Immunol. 2011;127(1):145-52. https://doi.org/10.1016/j.jaci.2010.10.020.

5. Sullivan PW, Ghushchyan VH, Slejko JF, Belozeroff V, Globe DR, Lin S-L. The burden of adult asthma in the United States: evidence from the medical expenditure panel survey. J Allergy Clin Immunol. 2011;127(2):363.e3-369.e3. https://doi.org/10.1016/j. jaci.2010.10.042.

6. Wang LY, Zhong Y, Wheeler L. Direct and indirect costs of asthma in school-age children. Prev Chronic Dis. 2005;2(1):A11.

7. American Lung Association. Asthma and children fact sheet. 2017. http://www.lung.org/lung-health-and-diseases/lung-disea se-lookup/asthma/learn-about-asthma/asthma-children-facts-sheet .html. Accessed 26 Apr 2018.

8. Barrett ML, Wier LM, Washington R. Trends in pediatric and adult hospital stays for asthma, 2000-2010: Statistical Brief \#169. Healthcare Cost and Utilization Project (HCUP) Statistical Briefs. Rockville: Agency for Healthcare Research and Quality (US); 2014.

9. Brandt SJ, Perez L, Kunzli N, Lurmannp F, McConnell R. Costs of childhood asthma due to traffic-related pollution in two California communities. Eur Respir J. 2012;40(2):363-70. https://doi. org/10.1183/09031936.00157811.

10. Hasegawa K, Tsugawa Y, Brown DF, Camargo CA Jr. Childhood asthma hospitalizations in the United States, 2000-2009. J Pediatr. 2013;163(4):1127.e3-1133.e3. https://doi.org/10.1016/j.jpeds .2013.05.002.

11. Karaca-Mandic P, Jena AB, Joyce GF, Goldman DP. Out-of-pocket medication costs and use of medications and health care services among children with asthma. JAMA. 2012;307(12):1284-91. https://doi.org/10.1001/jama.2012.340.

12. Pearson WS, Goates SA, Harrykissoon SD, Miller SA. State-based Medicaid costs for pediatric asthma emergency department visits. Prev Chronic Dis. 2014;11:E108. https://doi.org/10.5888/pcd11 .140139 .

13. Rust G, Zhang S, McRoy L, Pisu M. Potential savings from increasing adherence to inhaled corticosteroid therapy in Medicaid-enrolled children. Am J Manag Care. 2015;21(3):173-80.

14. Sullivan PW, Ghushchyan V, Navaratnam P, Friedman HS, Kavati A, Ortiz B, et al. The national cost of asthma among school-aged children in the United States. Ann Allergy Asthma Immunol. 2017;119(3):246.e1-252.e1. https://doi.org/10.1016/j. anai.2017.07.002.

15. Zhang Q, Zhao Y, Keshishian A, Xie L, Yuce H, Baser O. Evaluating asthma-related expenses and health care resource utilization among children in the United States medicaid population. Value Health. 2016;19(3):A114.

16. Centers for Disease Control and Prevention. Asthma severity among children with current asthma. 2015. https://www.cdc.gov/ asthma/asthma_stats/severity_child.htm. Accessed 15 Aug 2018.

17. Finkelstein JA, Barton MB, Donahue JG, Algatt-Bergstrom P, Markson LE, Platt R. Comparing asthma care for medicaid and non-medicaid children in a health maintenance organization. Arch Pediatr Adolesc Med. 2000;154(6):563-8. https://doi.org/10.1001/ archpedi.154.6.563.

18. Chang J, Freed GL, Prosser LA, Patel I, Erickson SR, Bagozzi RP, et al. Comparisons of health care utilization outcomes in children with asthma enrolled in private insurance plans versus Medicaid. J Pediatr Health Care. 2014;28(1):71-9. https://doi.org/10.1016/j. pedhc.2012.11.001.

19. Zahran H, Bailey C, Damon S, Garbe P, Breysse P. Vital signs: asthma in children-United States, 2001-2016. Morb Mortal Wkly Rep. 2018;67:149-55. https://doi.org/10.15585/mmwr. mm6705e1. 